\title{
Highly Selective Synthesis of Chlorophenols under Microwave Irradiation
}

\author{
Yawen Xiong, ${ }^{1}$ Hongdong Duan, ${ }^{1}$ Xia Meng, ${ }^{1}$ Zhaoyun Ding, ${ }^{1}$ and Weichun Feng ${ }^{2}$ \\ ${ }^{1}$ School of Chemistry and Pharmaceutical Engineering, Qilu University of Technology, Jinan 250353, China \\ ${ }^{2}$ Chemical Technology Academy of Shandong Province, Jinan 250014, China
}

Correspondence should be addressed to Hongdong Duan; hdduan@163.com

Received 7 February 2016; Accepted 17 March 2016

Academic Editor: Stojan Stavber

Copyright (C) 2016 Yawen Xiong et al. This is an open access article distributed under the Creative Commons Attribution License, which permits unrestricted use, distribution, and reproduction in any medium, provided the original work is properly cited.

Oxychlorination of various phenols is finished in 60 minutes with high efficiency and perfect selectivity under microwave irradiation. These reactions adopt copper(II) chloride $\left(\mathrm{CuCl}_{2}\right)$ as the catalyst and hydrochloric acid as chlorine source instead of expensive and toxic ones. Oxychlorination of phenols substituted with electron donating groups (methyl, methoxyl, isopropyl, etc.) at ortho- and meta-positions is accomplished with higher conversion rates, lower reaction time, and excellent selectivity. A proposed reaction mechanism is deduced; one electron transfers from $\mathrm{CuCl}_{2}$ to phenol followed by the formation of tautomeric radical that can be rapidly captured by chlorine atom and converts into para-substituted product.

\section{Introduction}

Chlorophenols are essential chemical intermediates in industry for the preparation of drugs, dyes, insecticides, herbicides, functional polymers, and so forth [1-3]. They are traditionally synthesized through electrophilic aromatic halogenations reactions [4], which are usually accompanied with the formation of byproducts including acetone and methylstyrene as well as high energy consumption [2]. Thus, it is necessary to develop green and effective method to produce these important materials.

As an alternative method, direct oxidative chlorination catalyzed by $\mathrm{CuCl}_{2}$ has been applied industrially to the conversion of ethylene into 1,2-dichloroethane [5], but there is very little literature reporting the oxychlorination of aromatics [6-8]. These reactions are usually carried out with poor selectivity and produce complex mixtures including mono- and poly-chloride substituted aromatic compounds $[7,8]$, which need further purification to get the desired products. Moreover, utilization of high value peroxo compounds such as m-chloroperbenzoic acid and potassium peroxomonosulfate is also an annoying problem $[7,8]$. After the cheapest dioxygen was found as the oxidant, researches on oxychlorination of aromatics become interesting and attractive. Menini and Gusevskaya reported the synthesis of chlorophenols catalyzed by $\mathrm{CuCl}_{2}$; dioxygen was used as oxidant and lithium chloride was the chlorinating agent $[9,10]$, by which the oxychlorination reaction could be conducted under mild conditions, but some of the compounds were obtained with low selectivity and long reaction time $[9,10]$.

Microwave-promoted organic synthesis has been rapidly developed as it can dramatically shorten the reaction time and save the energy in a variety of synthetic transformations [11]. This paper describes an economically and easy to handle way to synthesize chlorophenols catalyzed by $\mathrm{CuCl}_{2}$ under microwave irradiation. In this reaction, dioxygen is used as oxidant and hydrochloric acid as the chlorinating agent instead of expensive and toxic ones (Scheme 1).

\section{Experimental}

Chemical reagents were obtained from commercial sources and used without further purification. ${ }^{1} \mathrm{H}$ NMR spectra were recorded with a $400 \mathrm{MHz}$ Bruker AV III spectrometer. HRMS spectra (negative) were finished on a Thermo Electron LTQOrbitrap XL spectrometer. All the reactions were performed on a MCR-3 microreactor (Beijing Xianghu Science and 


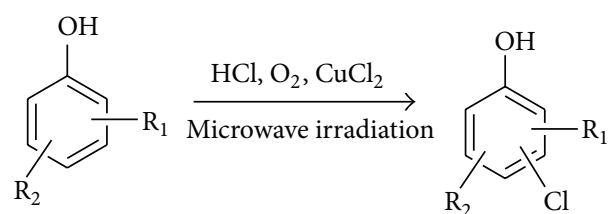

SCHEME 1: Microwave-promoted oxychlorination of phenols.

Technology Development Co., Ltd., Beijing, China) and measured by a gas chromatography (GC) using a Shimadzu GC-2014C instrument.

2.1. General Methods. Phenols $(78 \mathrm{mmol})$ and a catalytic amount of $\mathrm{CuCl}_{2}(7.8 \mathrm{mmol})$ were dissolved in $100 \mathrm{~mL}$ of aqueous hydrochloric acid solution $(6 \mathrm{~mol} / \mathrm{L})$, and the mixture was bubbled with dioxygen $(22 \mathrm{~mL} / \mathrm{min})$. The reaction was performed on a microreactor at $50^{\circ} \mathrm{C}$ and measured by gas chromatography (GC). After GC showed the disappearance of the starting material, the reaction was extracted with dichloromethane $(100 \mathrm{~mL} \times 2)$, and the organic layer was washed with water $(50 \mathrm{~mL} \times 2)$ and fractionated to give the desired product.

${ }^{1} \mathrm{H}$ NMR and HRMS spectra can be seen in the Supplementary Materials available online at http://dx.doi .org/10.1155/2016/2960414.

Compound lb: ${ }^{1} \mathrm{H}$ NMR (400 MHz, $\mathrm{CDCl}_{3}$ ) $\delta$ 7.24-7.17 (m, 2H, Ph), 6.77-6.74 (m, 2H, Ph), 5.27 (s, 1H, OH); HRMS (ESI-TOF) $m / z$ : calcd for $\mathrm{C}_{6} \mathrm{H}_{4} \mathrm{ClO}[\mathrm{M}-\mathrm{H}]^{-} 127.0029$, found 126.9956.

Compound 2b: ${ }^{1} \mathrm{H}$ NMR $\left(400 \mathrm{MHz}, \mathrm{DMSO}-d_{6}\right) \delta 9.20(\mathrm{~s}$, $1 \mathrm{H}, \mathrm{OH}), 6.95(\mathrm{~d}, J=2.0 \mathrm{~Hz}, 1 \mathrm{H}, \mathrm{Ph}), 6.79-6.75(\mathrm{~m}, 2 \mathrm{H}$, $\mathrm{Ph}), 3.78\left(\mathrm{~s}, 3 \mathrm{H}, \mathrm{OCH}_{3}\right.$ ); HRMS (ESI-TOF) $\mathrm{m} / z$ : calcd for $\mathrm{C}_{7} \mathrm{H}_{6} \mathrm{ClO}_{2}[\mathrm{M}-\mathrm{H}]^{-}$157.0135, found 157.0056.

Compound 3b: ${ }^{1} \mathrm{H}$ NMR $\left(400 \mathrm{MHz}, \mathrm{DMSO}-d_{6}\right) \delta 9.55$ (s, $1 \mathrm{H}, \mathrm{OH}), 6.94-6.90(\mathrm{~m}, 2 \mathrm{H}, \mathrm{Ph}), 6.76(\mathrm{dd}, J=3.2,8.8 \mathrm{~Hz}$, $1 \mathrm{H}, \mathrm{Ph}$ ), 3.69 (s, $3 \mathrm{H}, \mathrm{OCH}_{3}$ ); HRMS (ESI-TOF) $\mathrm{m} / z$ : calcd for $\mathrm{C}_{7} \mathrm{H}_{6} \mathrm{ClO}_{2}[\mathrm{M}-\mathrm{H}]^{-}$157.0135, found 157.0059.

Compound 4b: ${ }^{1} \mathrm{H}$ NMR $\left(400 \mathrm{MHz}, \mathrm{DMSO}-d_{6}\right) \delta 9.51(\mathrm{~s}$, $1 \mathrm{H}, \mathrm{OH}), 7.16(\mathrm{~d}, J=8.8 \mathrm{~Hz}, 1 \mathrm{H}, \mathrm{Ph}), 6.74(\mathrm{~d}, J=2.4 \mathrm{~Hz}$, $1 \mathrm{H}, \mathrm{Ph}$ ), 6.62 (dd, $J=2.8,8.8 \mathrm{~Hz}, 1 \mathrm{H}, \mathrm{Ph}), 2.24$ (s, 3H, $\mathrm{CH}_{3}$ ); HRMS (ESI-TOF) $m / z$ : calcd for $\mathrm{C}_{7} \mathrm{H}_{6} \mathrm{ClO}[\mathrm{M}-\mathrm{H}]^{-}$141.0185, found 141.0116.

Compound 5b: ${ }^{1} \mathrm{H}$ NMR (400 MHz, DMSO- $\left.d_{6}\right) \delta 10.93$ $(\mathrm{s}, 1 \mathrm{H}), 10.23(\mathrm{~s}, 1 \mathrm{H}), 7.60(\mathrm{~d}, J=2.8 \mathrm{~Hz}, 1 \mathrm{H}, \mathrm{Ph}), 7.54(\mathrm{dd}, J=$ 2.8, $8.8 \mathrm{~Hz}, 1 \mathrm{H}, \mathrm{Ph}$ ), 7.05 (d, $J=8.8 \mathrm{~Hz}, 1 \mathrm{H}, \mathrm{Ph}$ ); HRMS (ESITOF) $m / z$ : calcd for $\mathrm{C}_{7} \mathrm{H}_{4} \mathrm{ClO}_{2}[\mathrm{M}-\mathrm{H}]^{-} 154.9978$, found 154.9898 .

Compound 6b: ${ }^{1} \mathrm{H}$ NMR (400 MHz, DMSO- $\left.d_{6}\right) \delta 9.39$ (s, 1H, OH), 7.04 (s, 1H, Ph), $6.72(\mathrm{~s}, 1 \mathrm{H}, \mathrm{Ph}), 3.15-3.12$ $\left(\mathrm{m}, 1 \mathrm{H}, \mathrm{CH}\left(\mathrm{CH}_{3}\right)_{2}\right), 2.19\left(\mathrm{~s}, 3 \mathrm{H}, \mathrm{CH}_{3}\right), 1.12(\mathrm{~d}, J=$ $6.8 \mathrm{~Hz}, 6 \mathrm{H}, \mathrm{CH}\left(\mathrm{CH}_{3}\right)_{2}$ ); HRMS (ESI-TOF) $\mathrm{m} / z$ : calcd for $\mathrm{C}_{10} \mathrm{H}_{13} \mathrm{ClO}[\mathrm{M}-\mathrm{H}]^{-}$183.0655, found 183.0579.

Compound $7 \mathbf{b}:{ }^{1} \mathrm{H}$ NMR $\left(400 \mathrm{MHz}, \mathrm{DMSO}-d_{6}\right) \delta 9.52(\mathrm{~s}$, $1 \mathrm{H}, \mathrm{OH}), 7.10(\mathrm{~d}, J=2.4 \mathrm{~Hz}, 1 \mathrm{H}, \mathrm{Ph}), 7.01(\mathrm{dd}, J=2.8,8.4 \mathrm{~Hz}$, $1 \mathrm{H}, \mathrm{Ph}), 6.78(\mathrm{~d}, J=8.8 \mathrm{~Hz}, 1 \mathrm{H}, \mathrm{Ph}), 2.11\left(\mathrm{~s}, 3 \mathrm{H}, \mathrm{CH}_{3}\right)$; HRMS
(ESI-TOF) $m / z$ : calcd for $\mathrm{C}_{7} \mathrm{H}_{6} \mathrm{ClO}[\mathrm{M}-\mathrm{H}]^{-} 141.0185$, found 141.0107.

\section{Results and Discussion}

3.1. Oxychlorination of Phenols. Oxychlorination of various phenols was performed to investigate the reactivities (Table 1). Under microwave irradiation, 4-chlorophenol was prepared with high efficiency (93.4\%) and perfect selectivity $(96.6 \%)$, and the reaction was finished only in 60 minutes at $50^{\circ} \mathrm{C}$ (Entry 1) with minor amounts of orthosubstituted products being detected. Oxychlorination of phenols substituted by electron donating groups (methyl, methoxyl, isopropyl, etc.) at ortho- and meta-positions was accomplished with higher conversion rates, lower reaction time, and excellent selectivity. In particular, compound 6a, simultaneously substituted by methyl and isopropyl groups at ortho- and meta-positions, completed the conversion with $100 \%$ efficiency and $99.8 \%$ selectivity (Entry 6). Furthermore, oxychlorination of ortho-substituted phenol with aldehyde group was still finished with high efficiency and excellent selectivity (Entry 5) but in 50 minutes. Substituting phenol with methoxyl group (3a) at para-position, the oxychlorination reaction occurred at ortho-position with lower conversion rate and poor selectivity due to the dual-orienting effect (Entry 3).

3.2. Proposed Reaction Mechanism. Different conditions were researched to investigate the proposed reaction mechanism in oxychlorination of phenol. As it is shown in Table 2, without addition of hydrochloric acid, there was no chlorination product detected in this reaction, and the chlorination efficiency was only $10.3 \%$ when hydrochloric acid was replaced with sulfuric acid, which indicated that hydrochloric acid was performed as chlorine source. As the catalyst, $\mathrm{CuCl}_{2}$ played an essential role in chlorination reaction. In the absence of $\mathrm{CuCl}_{2}$, no product was formed and no other reactions were occurred, and replacement of $\mathrm{CuCl}_{2}$ by lithium chloride still could not promote the reaction. Furthermore, the conversion rate was relatively low when the procedure was not bubbled with dioxygen, which proved its participation in oxidation.

A proposed reaction mechanism is depicted in Scheme 2. As conventional mechanism of phenol chlorination [9], one electron transfers from $\mathrm{Cu}(\mathrm{II})$ to phenoxy radical $\mathbf{B}$ via the complex A and simultaneously generates copper(I) chloride $(\mathrm{CuCl})$. Then, radical $\mathbf{B}$ converts to the tautomeric structure $\mathrm{C}$, followed by chlorination with $\mathrm{CuCl}_{2}$ to form intermediate product $\mathbf{D}$ and $\mathrm{CuCl}$. Tautomerization of $\mathbf{D}$ affords the desired product 4-chlorophenol, and $\mathrm{CuCl}$ generated in this reaction converts to $\mathrm{CuCl}_{2}$ in the presence of hydrochloric acid and dioxygen. Our previous experiments revealed that insufficient concentration of $\left[\mathrm{H}^{+}\right]$caused the transformation of radical $\mathbf{C}$ to benzoquinone. Furthermore, major byproduct monitored in this reaction was 2-chlorophenol which was generated from tautomerization of radical $\mathbf{C}$ into $\mathbf{E}$, and further conversions as the similar procedure to form 4chlorophenol gave the ortho-substituted product. It seems that the key step of the reaction is the formation of radicals 
TABLE 1: Oxychlorination of phenols under microwave irradiation.

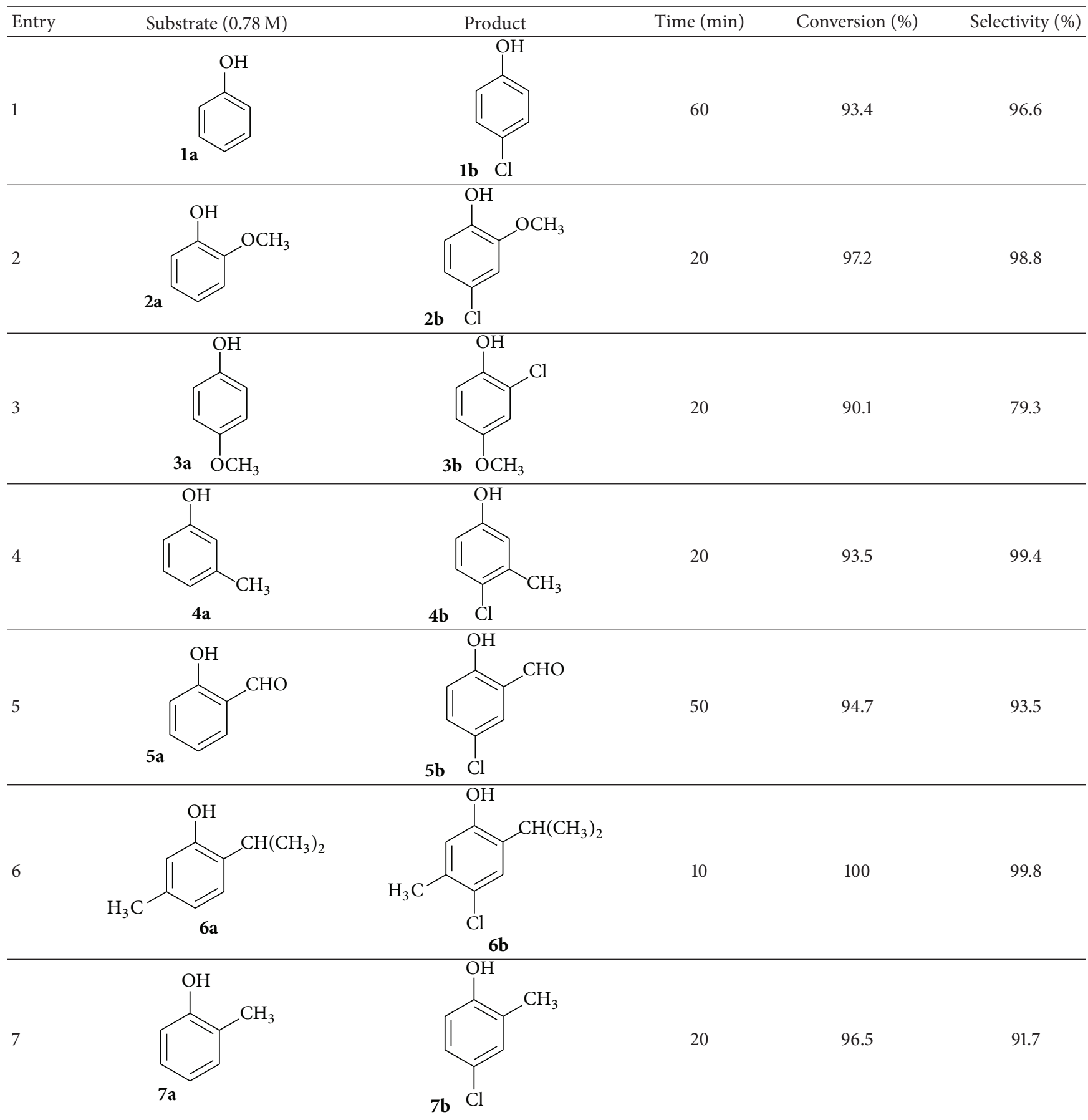

Conditions: microwave irradiation; solvent, aqueous hydrochloric acid solution $(6 \mathrm{~mol} / \mathrm{L})$; reaction temperature $\left(50^{\circ} \mathrm{C}\right)$. Conversion and selectivity were determined by GC.

C, and they are easily and rapidly captured by chlorine atoms compared with radicals E. Due to the high efficiency and perfect selectivity of this reaction, we deduce that microwave irradiation promoted the generation of radicals $\mathbf{C}$, and their chlorination occurs faster than the traditional methods. And microwave irradiation seems to prevent the tautomerization of radicals $\mathbf{C}$ into $\mathbf{E}$, which may be caused by the lower reaction temperature.

\section{Conclusions}

This paper describes the preparation of various chlorophenols promoted by microwave irradiation. Copper(II) chloride is used as the catalyst and hydrochloric acid as chlorine source instead of expensive and toxic ones. Using phenols substituted with electron donating groups at ortho- and meta-positions as substrates generates chlorophenols with 
TABLE 2: Oxychlorination of phenol.

\begin{tabular}{|c|c|c|c|c|c|}
\hline Entry & Acid & Catalyst & Dioxygen flow rate $(\mathrm{mL} / \mathrm{min})$ & Conversion (\%) & Selectivity (\%) \\
\hline 1 & - & $\mathrm{CuCl}_{2}$ (0.1 eq.) & $\mathrm{O}_{2}(22 \mathrm{~mL} / \mathrm{min})$ & - & - \\
\hline 2 & - & $\mathrm{CuCl}_{2}$ (2 eq.) & $\mathrm{O}_{2}(22 \mathrm{~mL} / \mathrm{min})$ & - & - \\
\hline 3 & $\mathrm{HCl}(6 \mathrm{~mol} / \mathrm{L})$ & $\mathrm{CuCl}_{2}$ (0.1 eq.) & - & 30.2 & 96.3 \\
\hline 4 & $\mathrm{HCl}(6 \mathrm{~mol} / \mathrm{L})$ & - & $\mathrm{O}_{2}(22 \mathrm{~mL} / \mathrm{min})$ & - & - \\
\hline 5 & $\mathrm{HCl}(6 \mathrm{~mol} / \mathrm{L})$ & $\mathrm{CuCl}_{2}$ (0.1 eq.) & $\mathrm{O}_{2}(22 \mathrm{~mL} / \mathrm{min})$ & 93.4 & 96.6 \\
\hline 6 & $\mathrm{HCl}(6 \mathrm{~mol} / \mathrm{L})$ & $\mathrm{CuCl}_{2}$ (2 eq.) & $\mathrm{O}_{2}(22 \mathrm{~mL} / \mathrm{min})$ & 94.1 & 96.9 \\
\hline 7 & $\mathrm{HCl}(2 \mathrm{~mol} / \mathrm{L})$ & $\mathrm{CuCl}_{2}$ (0.1 eq.) & $\mathrm{O}_{2}(22 \mathrm{~mL} / \mathrm{min})$ & 77.7 & 95.7 \\
\hline 8 & $\mathrm{HCl}(6 \mathrm{~mol} / \mathrm{L})$ & $\mathrm{LiCl}$ (2 eq.) & $\mathrm{O}_{2}(22 \mathrm{~mL} / \mathrm{min})$ & 3.1 & 93.1 \\
\hline 9 & $\mathrm{H}_{2} \mathrm{SO}_{4}(6 \mathrm{~mol} / \mathrm{L})$ & $\mathrm{CuCl}_{2}$ (2 eq.) & $\mathrm{O}_{2}(22 \mathrm{~mL} / \mathrm{min})$ & 10.3 & 96.0 \\
\hline
\end{tabular}

Conditions: microwave irradiation; solvent, $\mathrm{H}_{2} \mathrm{O}$ for 1-2, aqueous hydrochloric acid solution for 3-8, aqueous sulfuric acid solution for 9; reaction time (60 min); reaction temperature $\left(50^{\circ} \mathrm{C}\right)$. Conversion and selectivity were determined by GC.

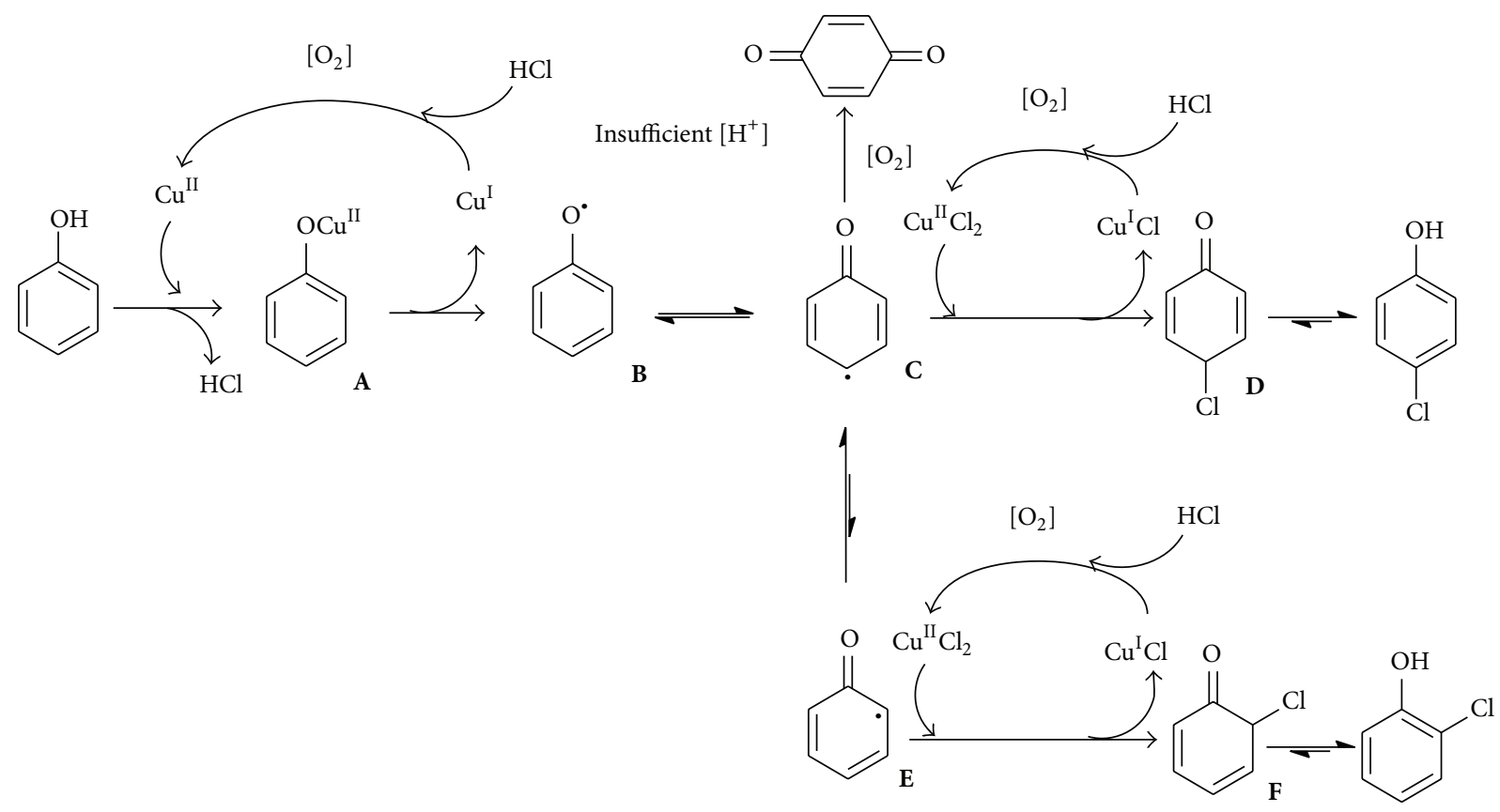

SCHeme 2: Proposed reaction mechanism of oxychlorination of phenol.

higher conversion rates, lower reaction time, and excellent selectivity, and no polychlorination products are detected. From a proposed reaction mechanism, we deduce that the reaction is inclined to form tautomeric radicals $\mathbf{C}$ that can be rapidly captured by chlorine atoms and convert into parasubstituted products.

\section{Competing Interests}

The authors declare that there is no conflict of interests regarding the publication of this paper.

\section{Acknowledgments}

This work is supported by the Project of Shandong Province Science and Technology Development Plan (Grant no. 2014GGX102023).

\section{References}

[1] J. M. Gnaim and R. A. Sheldon, "Shape-selective parachlorination of phenol using sulfuryl chloride with the aid of microporous catalysts," Tetrahedron Letters, vol. 45, no. 51, pp. 9397-9399, 2004.

[2] O. Shoji, T. Kunimatsu, N. Kawakami, and Y. Watanabe, "Highly selective hydroxylation of benzene to phenol by wild-type cytochrome P450BM3 assisted by decoy molecules," Angewandte Chemie -International Edition, vol.52, no. 26, pp. 66066610, 2013.

[3] Y. Li, B. Li, L. Geng, J. Wang, Y. Wang, and J. Huang, "The hydroxylation of aromatics with oxygen by vanadium catalysts supported on N-doped carbon materials," Catalysis Letters, vol. 145, no. 4, pp. 1014-1021, 2015.

[4] R. J. Schmidt, "Industrial catalytic processes-phenol production," Applied Catalysis A: General, vol. 280, no. 1, pp. 89-103, 2005. 
[5] C. U. Dinesh, R. Kumar, B. Pandey, and P. Kumar, "Catalytic halogenation of selected organic compounds mimicking vanadate-dependent marine metalloenzymes," Journal of the Chemical Society, Chemical Communications, no. 6, pp. 611-612, 1995.

[6] R. Raja and P. Ratnasamy, "Oxyhalogenation of aromatics over copper phthalocyanines encapsulated in zeolites," Journal of Catalysis, vol. 170, no. 2, pp. 244-253, 1997.

[7] K. H. Chung, H. J. Kim, H. R. Kim, and E. K. Ryu, "Oxidative chlorination of phenols with hydrogen chloride/mchloroperbenzoic acid/N,N-dimethylformamide system," Synthetic Communications, vol. 20, no. 19, pp. 2991-2997, 1990.

[8] N. Narender, K. V. V. K. Mohan, P. Srinivasu, S. J. Kulkarni, and K. V. Raghavan, "A simple, efficient and regioselective oxychlorination of aromatic compounds using ammonium chloride and oxone ${ }^{\circledR,}$, Indian Journal of Chemistry Section B: Organic and Medicinal Chemistry, vol. 43, no. 6, pp. 1335-1338, 2004.

[9] L. Menini and E. V. Gusevskaya, "Aerobic oxychlorination of phenols catalyzed by copper (II) chloride," Applied Catalysis A: General, vol. 309, no. 1, pp. 122-128, 2006.

[10] L. Menini and E. V. Gusevskaya, "Novel highly selective catalytic oxychlorination of phenols," Chemical Communications, no. 2, pp. 209-211, 2006.

[11] K. V. V. K. Mohan, N. Narender, and S. J. Kulkarni, “Zeolite catalyzed acylation of alcohols and amines with acetic acid under microwave irradiation," Green Chemistry, vol. 8, no. 4, pp. 368-372, 2006. 

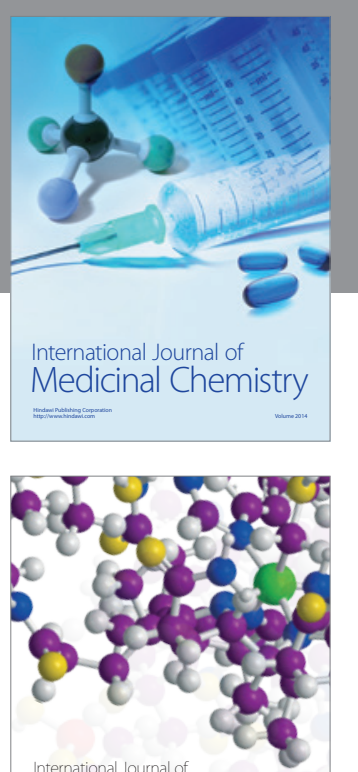

Carbohydrate Chemistry

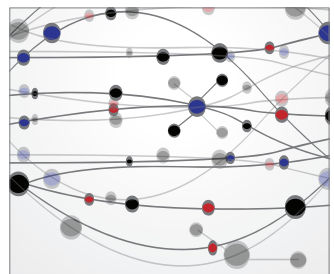

The Scientific World Journal
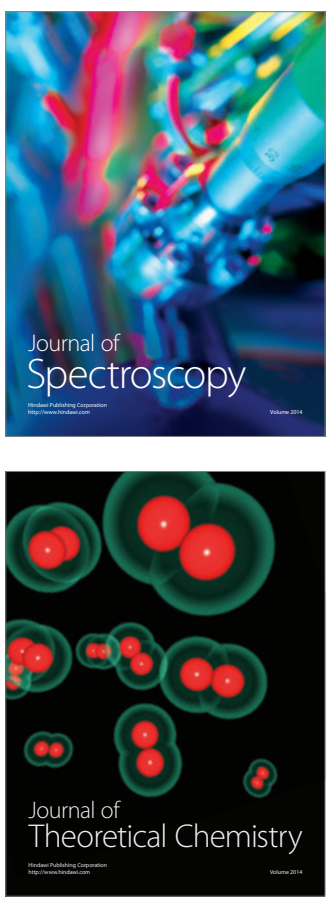
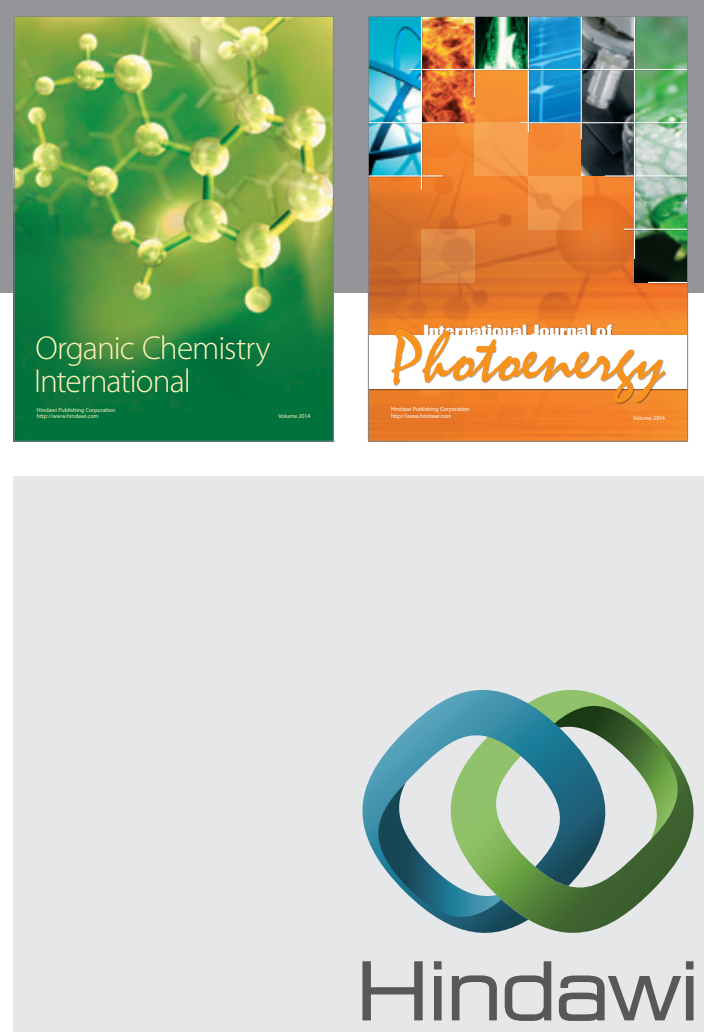

Submit your manuscripts at

http://www.hindawi.com

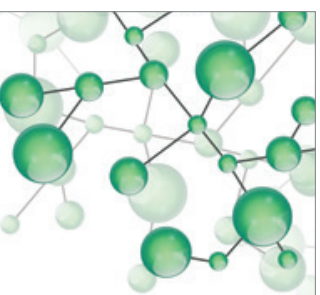

International Journal of

Inorganic Chemistry

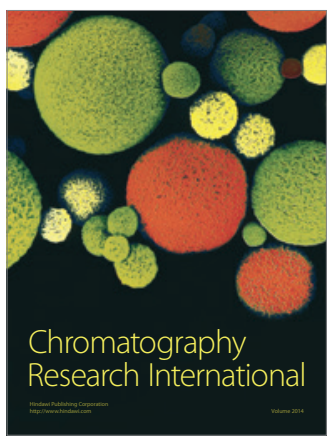

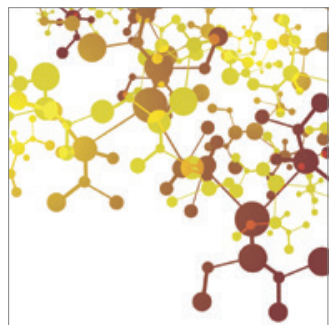

Applied Chemistry
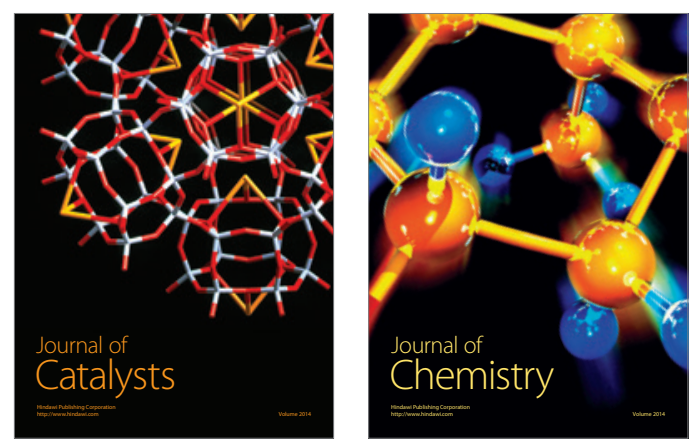
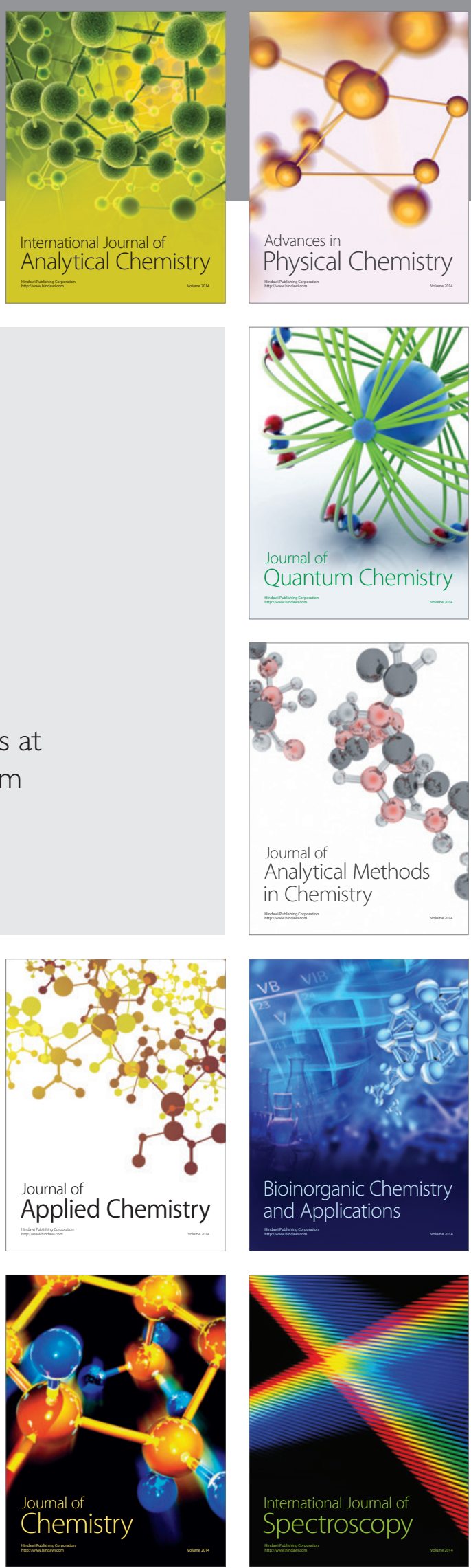